\title{
RAIL ROAD WHEEL REQUIREMENTS AND MANUFACTURING PROCESSES
}

\author{
ASHWANI SHARMA ${ }^{1}$, M. A. MURTAZA ${ }^{2} \&$ M. I. MURTAZA ${ }^{3}$ \\ ${ }^{\text {I}}$ Assistant Professor, ASET, Amity University, Lucknow Campus, Uttar Pradesh, India. \\ ${ }^{2}$ Professor ASET, Amity University, Lucknow Campus, Uttar Pradesh, India. \\ ${ }^{3}$ Member, The American Society of Mechanical Engineers, India.
}

\begin{abstract}
A railroad wheel has evolved over the last two centuries with increasing load and speed. A harder wheel maintains its geometry and therefore is able to negotiate the track without giving rise to high forces. This paper describes pressure poured cast wheel and forged wheel manufacturing processes. As experimentally verified on other railways, pressure poured cast wheels have been used satisfactorily in locomotive and passenger services in the Indian railways where conventionally forged wheels were used worldwide.

KEY WORDS: Railroad, Cast Wheels, Forged Wheel, Pressure Poured Casting, Thermal Load, Fatigue Strength, Hardness \& Rail-Wheel Interaction.
\end{abstract}

Received: Jan 15, 2018; Accepted: Feb 05, 2018; Published: Feb 26, 2018; Paper Id.: IJMPERDAPR201810

\section{INTRODUCTION}

The wheel was invented in around $3500 \mathrm{BC}$ and was used for transportation under a chariot in $3200 \mathrm{BC}$ in Mesopotamia[1]. Railways came into existence in the beginning of the 19th century and railroad wheels were required to support the weight as well as guide the vehicle. In the beginning, wheels were built up with or without spoke and now railroad wheels are mono block. Wise [2] has given the history of evolution of railroad wheel sets.

Initially rail-wheel mechanics was enough to solve problems and improve the system. Demand for higher speed and load started increasing and the need to improve efficiency required further investigation and studies. The next level of system was rail-vehicle interaction and then with the advent of heavy-haul and high-speed operation, it required the studies of track-train dynamics [3, 4]. The wheel is the most important for the safety and stability of a guided vehicle.

\section{Rail Road Wheel}

A railroad car is directionally guided by the tracks on which they operate. Therefore a railroad wheel not only supports the weight of a car, but also the thermal and mechanical stresses caused during train operation.

A typical wheel set is shown in fig. 1. As shown in Fig.2, a railroad wheel consists of three parts, a hub, a rim and a web. Thread is the outer circumferential surface of the rim and its project part is called flange.

The rim width and thickness, hub diameter and length and position of rim relative to the hub (Fig. 2) are wheel parameters dictated by service requirements or railroad regulations. The web shape, however, can take on many forms.

Railroad wheel life [5] is determined by various factors such as wear, shelling and thermal cracking of the wheel tread, fatigue of wheel plates and fracture. 


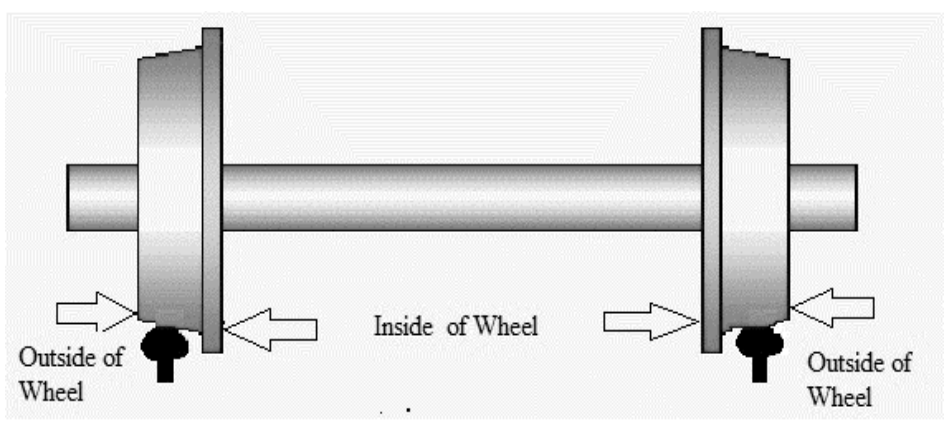

Figure 1: Rail Road Wheel Set on Rails

Optimum designs, from a service standpoint of a rail road wheel [6], are those which can best withstand the combined effects of stresses resulting from the following conditions:

- $\quad$ Thermal load due to brake application. These do not fluctuate during wheel revolution.

- Mechanical loads in vertical direction (V) are due to equipment and loading of the railroad car. They apply at wheel tread and fluctuate once in each revolution. These may have dynamic augmentation due to track deviation and operation.

- Mechanical loads in the lateral direction (L) apply at the tread or the flange during curve negotiation or vehicle stability such as hunting, and nosing. These also fluctuate during each revolution of the wheel.

- $\quad$ Driving wheels exert a tractive load at rail-wheel contact area. These also fluctuate.

\section{PERFORMANCE REQUIREMENTS}

\section{Kinds of Mechanical Loads}

Figure 2 shows the mechanical loads exerted on a railroad wheel. These loads at the rail - wheel interface are also considered for the stability analysis of a railroad vehicle [7].

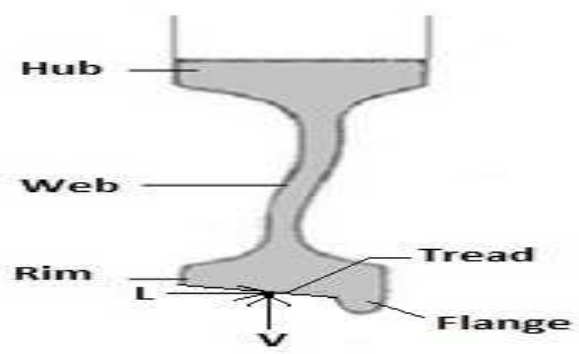

Figure 2: Wheel Disc of a Rail Road Wheel

\section{Mechanical Stresses at the Tread}

A new wheel of $916 \mathrm{~mm}$ diameter with standard contour supporting a $100 \mathrm{k} \mathrm{N}$ load on a new rail produces a calculated area of contact of about $159 \mathrm{~mm}^{2}$ [8]. This results in concentration of very high stress, which is cyclic and gives ideal conditions for fatigue failure.

A serious effect of mechanical stress at the tread is shelling. This is a fatigue failure due to contact stresses and is to be found on wheels having high static or dynamic loads. The magnitude of this effect is directly related to the geometry of the wheel and rail, the vertical wheel/rail forces and speed. 


\section{Thermal Load Due to Tread Braking}

Railroad wheel is also used for brake application. Therefore, frictional heat is generated and transferred to tread, which tends to expand rim radially. This expansion is restrained by the web which is at a lower temperature, consequently stresses are produced in the web. These stresses are much higher than those induced by mechanical loading.

Drag braking, when temperatures can reach the $600-700^{\circ} \mathrm{C}$ range, produces higher web stresses than stop braking where temperatures are in the range $100-300^{\circ} \mathrm{C}$ depending on speed and braking time [8].

\section{Reversal Residual Compressive Stress}

Compressive residual stress, improves the fatigue life of a railroad wheel. Therefore, compressive residual stress is induced during heat treatment, which is part of the manufacturing process. When brakes are applied, frictional heat is generated on the tread of the railroad wheel, therefore braking heats the whole rim to a high temperature. In turn rim expands and pulls the web outward. It results in generation of tensile stress, when it exceeds the yield stress, outward plastic deformation of the web takes place. During brake release, temperature drops, and rim cools down, but web does not allow to contract, because of plastic deformation of web. So, reversal of residual compressive stress takes place in the rim. It results in the loss of fatigue life [9].

\section{WHEEL MATERIAL}

Earlier low carbon steel (around 0.5\%), was in use in Europe [2]. It was expected that the increase in carbon content will improve wheel life, but it may increase rail wear.

A number of studies were conducted to find the effect of higher carbon content in the wheel material and rail. Dr. Saito et al did investigations on a miniature car, a 1/3 scale model for seven years. They measured rail and wheel wear. They found that the increase in carbon content of wheel material has resulted in reduction of wear in the wheel as well as the rail. German Railway (DB) did experiments on full size wheels as well as they collected the wear data of wheels of actual train operation. From these it was concluded that rail wear is not effected by the increase in carbon content in the wheel material [10].

Mutton and Epp [12] found that on 20 tonne axle load tests, the wear rate of standard carbon rails at high flanging stresses is higher for softer wheel materials. They attributed the increase in rail wear rate to be partly due to the deterioration of wheel flange profile by both wear and plastic flow, giving rise to more severe contact conditions. Higher strength materials are likely to retain modified profiles for longer periods. In other words a hard wheel maintains its geometrical profile and therefore able to negotiate the track without giving rise to high forces, which finally results in less wear of the rail.

\section{MANUFACTURING OF WHEELS}

Rail road wheels are manufactured either by directly casting from the liquid metal into finished shape or by forming from solid blocks of ingot through a sequence of the hot forging process.

The characteristic feature required for the passenger car and the locomotive wheels is reliability and that required for the freight car wheel is initial maintenance cost. Forging gives a better finish and a good grain structure and therefore has been adopted for passenger car and locomotive wheels whereas cast wheels have been adopted for freight stock 
wheels.

Wheel/ Rail wear testing was conducted on test stand [11]. The comparison was between Forged/ rolled wheels and pressure poured cast wheels using AAR's class-B \&Class-C chemistry (Table-1) and it was clear from the results that the class $\mathrm{C}$ pressure poured cast wheel has no adverse effect on rail wear. In fact, both the wheel wear and rail wear are significantly less for class C cast wheel.

Table 1: AAR: Steel Grades

\begin{tabular}{|l|c|c|}
\hline Steel Grade (Class) & Carbon Content Range & Hardness Range \\
\hline A & 0.47 to 0.57 & 255 to 321 \\
\hline B & 0.57 to 0.67 & 302 to 341 \\
\hline C & 0.67 to 0.77 & 321 to 363 \\
\hline D & 0.67 to 0.77 & 341 to 415 \\
\hline
\end{tabular}

\section{Cast Wheel}

In cast wheel manufacturing, Electric Arc Furnace is used to get molten steel. The charge comprises of superior scrap steel obtained from old wheels, axles, rails etc and correct chemistry of molten steel is ensured. The molten steel is transferred to a ladle, where alloying and micro-cleaning is done. The ladle is kept inside the John Mohr pit (Fig. 5), which is a sealed chamber with an airtight cover. Airtight cover supports a preheated and sprayed graphite mold to which a ceramic tube is connected. Molten steel is forced into the mold by controlling air pressure. This process gives precision cast wheel and gives clean steel as re-oxidation is eliminated in the airtight chamber. The top of the mold (cope) is removed and cast wheel taken out for cooling. Then risers are removed on grinding machine and the hub is cut.

After this wheel is normalized, rim is hardened by water spray. It is followed by tempering and shot blasting of wheel, online ultrasonic testing and hardness testing. Finally, compressive stresses are induced by shot peening

Block diagram shows the sequence of cast wheel manufacture.

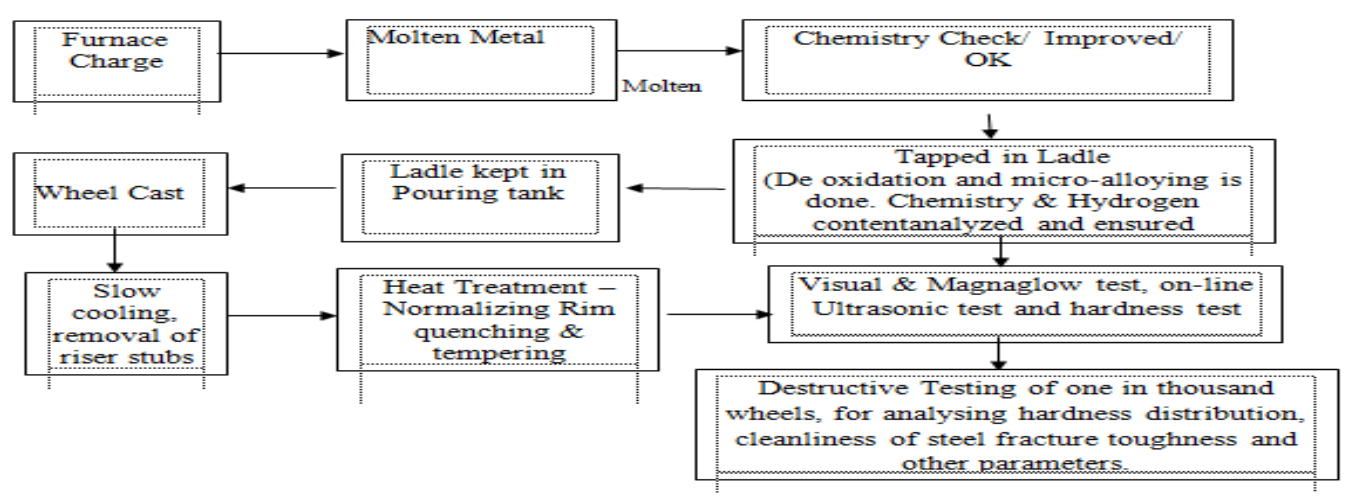

Figure 4: Flow Diagram of Cast Wheel Manufacture 


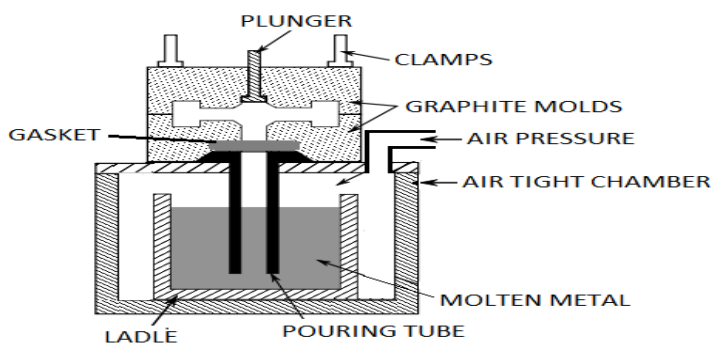

Figure 5: Pressure Poured Cast Wheel

M/s Griffin Wheel Co. USA, pioneered this technology in 1964, and is in use in India also.

ABC-NACO's casting process uses composite mold which is graphite at the tread of wheel and internal plate section uses sand. It solidifies from outside, which creates 'uni-axial' distribution.

\section{Forged Wheel}

Ingot surfaces are visually inspected for the detection of casting defects. The bottom portions of the ingots are dressed i.e. runners and fins are eliminated by oxy-acetylene torch. Band saw machines are used to cut the ingots to the specified length, to obtain blocks called 'chese', to the required weight depending on the type of wheel. Blocks are then charged to the gas fired Rotary Hearth Block heating furnace for heating before forging operation. De-scaled blocks are then pressed on a hydraulic wheel press.

Wheel forging operation consists of upsetting, forging and punching the bore. The block takes the shape of the die with centrally raised portion, which forms the hub. The wheel shape is formed, but without central bore and is called 'wheel blank'. To achieve this bore, a hole is pierced in the third operation known as hub punching. Shapes formed by press forging are generally dense and homogeneous in structure. It exhibits directional properties and develops internal stresses during forming, which are subsequently relieved by heat treatment. Wheel blanks are visually checked for forging defects.

Forged wheel blanks are reheated. The wheel rolling process is a unique metal forming operation, which uses various rolls simultaneously to form the profile. Wheel blanks are rolled in a vertical wheel rolling mill. Then the wheels are pressed on a dishing press to produce a nearly accurate profile on the web. The dishing operation restores radial and axial symmetry of the wheel, It also straightens the rim portion of the wheel.

Wheels are then subjected to heat treatment, (rim quenching, tempering) to improve the physical and mechanical properties as per the specified requirement.

Standard Steel USA and SAIL India produce forged wheels. 


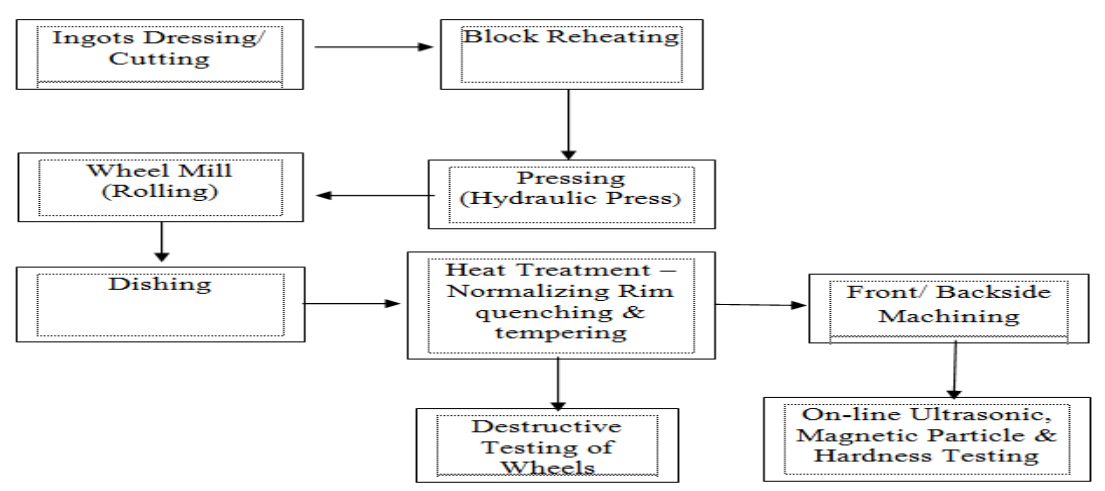

Figure 6: Flow Diagram of Forged Wheel Manufacture

\section{Manufacturing of Wheels \& Axles in RWF Bangalore, India}

Indian Railways run every day 7500 freight trains and 13000 passenger trains, which is one of the largest network in the world. Both the freight and passenger services are equally important.

Indian Railways has two number of wheel manufacturing plants, one at Bangalore in Karnataka and the other at Chapra in Bihar. Both these plants use cast wheel technology of M/s Griffin USA.

Prior to these wheels were procured from Steel Authority of India(SAIL) and import.

RWF (Rail Wheel Factory) at Bangalore came up in 1978. This production unit produces cast wheels and forged axles [13-15]. Later on, plant at Chapra came up for manufacturing of cast wheels only.

Initial capacity of RWF was 50,000 wheels and now it has gone up to $200,000 \mathrm{p}$. a. This was possible by reducing bottle necks, idle time, adopting parallel activities, multiple ladle operation and automation.

Axles

Manufacture of axles follows the sequence similar to that used for forged wheel manufacture.

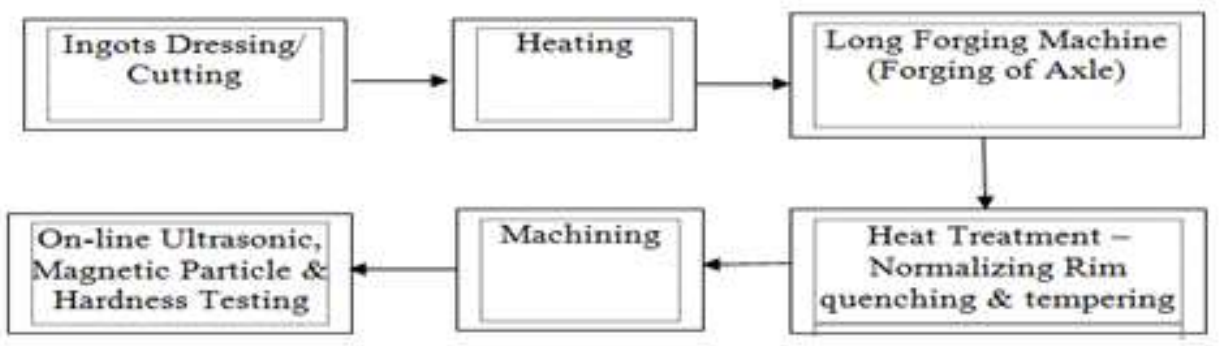

Figure 7: Flow Diagram of Forged Axle Manufacture

The Plant converts steel blooms to axles through a series of forging, heat treatment and machining processes.

Axles manufacturing process uses billets, which are obtained by cutting high-quality vacuum degassed steel blooms. Heated billets are forged into axles on a special purpose precision Forging Machine. After forging, axles are machined, and quality tests are conducted. 


\section{Wheel Sets}

Wheels and axle are assembled to get a wheel set in a wheel assembly complex.

Wheel seat sizes of machined axles are measured, and wheels received from wheel shop are bored according to this size. The precision borers ensure that the final bores have required interference with the individual axles. After boring, the wheels are carried through automated conveyors to the assembly complex along with axles and wheels are pressed one after another. The force required in pressing the wheels is recorded automatically to ensure that the pressing force is within the laid down limits.

\section{Diversification of Cast Wheels}

Initially this plant (RWF) was set up only for the freight stock (BOXN) wheels. Locomotive stock and Coaching stock wheels were forged wheels and were obtained from SAIL India and import as reliability was the prime consideration.

Experience of manufacture of cast wheels for freight stock and their performance was gained over years. There was no online failure of these cast wheels produced by RWF Bangalore. Therefore, manufacturing process was adopted for Loco and Coaching wheels and their performance was found satisfactory.

Apart from manufacturing freight stock cast wheels (BOXN, Container flat) RWF Bangalore is also manufacturing coaching stock cast wheels of BG and MG, Locomotive wheels of BG and MG and suburban and intercity EMU cast wheels $[13,14]$.

Railways have been experimentally confirming the capability of cast wheel applications [11] in the past and now it has been implemented satisfactorily over Indian Railways.

\section{Production over the Years}

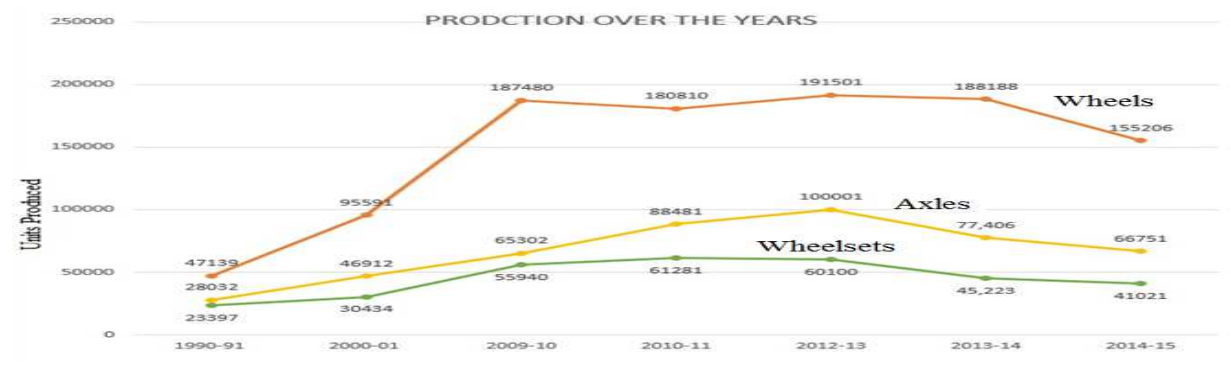

Figure 8: Production of RWF

Figure 8 shows the production of Cast wheels, forged axles and wheel sets of Rail Wheel factory (RWF) Bangalore. Initially 50,000 wheels and 28000 axles were produced. Production capacity has increased over the years by resorting to automation and augmenting the capacity at bottlenecks. Now a figure of production 200,000 wheels and 100,000 axles is achievable. There is a drop in production due to reduction in demand and change in product mix. Change in product requires additional set up time.

\section{CONCLUSIONS}

Following conclusions are drawn from this study;

- A railroad wheel has to be toughest as it has to support the weight of the rail road vehicle and get guided by the 
lateral forces on track. In addition, it has to sustain braking and thermal loads. It has to be strong enough to resist wear, crack and fracture.

- Wheel material plays a very important role. A harder wheel maintains its geometry and therefore able to negotiate track without giving rise to high forces, which in turn results in less wear of the rail.

- Manufacture of wheels involves either forging from a bloom or casting from pedigree scrap. Forging is generally considered a superior manufacturing process. Performance in field indicates that the quality system is important for the manufacturing process. Cast wheels are performing satisfactorily on passenger cars and locomotives on Indian Railways. This aspect was only experimentally verified on other Railway systems.

- Further increase in load and speed will require improved material properties and design of the wheel.

Multiple wear wheels are in use on Indian Railways. It extends the life of a wheel. Wheels withdrawn from service due to sharp flange are reclaimable by flange welding and machining.

Particularly cast wheels use pedigree scrap, which is a recycling process. So, there is a scope of developing processes for remanufacturing instead of recycling wheels, withdrawn from service.

\section{REFERENCES}

1. http://www.ideafinder.com/history/inventions/wheel.htm

2. S. Wise (1987) Railway Wheel sets-a Critical Review. Proceedings of the I. Mech. E. Part D: Journal of Automobile Engineering 201(4) 257-271.

3. M. A. Murtaza, S. B. L. Garg (1989) Brake Modelling in Train Simulation Studies. Proceedings of the I. Mech. E. PartF: Journal of Rail and Rapid Transit 203(2) 87-95.

4. M. A. Murtaza, S L. Garg (1990)Transients During a Railway Air Brake Release Demand. Proceedings of the I. Mech. E. Part F: Journal of Rail and Rapid Transit204 (1)31-38.

5. K. Hirakawa, H. Sakamoto (1981) Effect of Design Variation on Railroad Wheel Fracture. ASME paper 91-WA/RT-41.

6. J. P. Bruner, R. D. Jones, Samuel Levy, J. M. Wandrisco (1968) Effect of Design Variation on Service Stresses in Railroad Wheels. ASME 187-196., Paper No. 67- WA/RR-6.

7. Kasy Aiyar (1976) Some Aspects of the Problem of Rail-Wheel Interaction. Research Design and Standards Organisation, India, Technical Report No.345, 1976:1.

8. M. Gay (1979) The modern Wheel set. International Conference on Railway Braking, SP21 26-27 Sep. 1979. (Sponsored by Railway division of I. Mech. E.)

9. R I Stephens, A Fatimi, R. R. Stephens, H O Fuchs Metal Fatigue in Engineering. Second Edition, John Wiley and Sons Inc. page 75 .

10. Yoshinori Okagata (2013) Design Technologies for Railway Wheels and Future Prospects. Nippon Steel \& Sumitomo Metal Technical report no. 105 26-33.

11. Cameron L, Roman B, Mark Norton (2011) Application of Pressure Poured Cast Wheel Technology for European Freight Service.9th World Congress-Railway Research 22-26. 
12. P J Mutton, C J Epp (1983) Factors influencing Rail and Wheel Wear. Proceedings of the Railway Engineering Symposium, Melbourne, Australia 216-221.

13. Website: rwf.indianrailways.gov.in

14. R. Bhargav (2014) Enhancing the Productivity and Capability of the Rail Wheel Factory Bangalore. Indian Foundry Journal, Vol 60 (5) 34-46.

15. Ashwani S, Murtaza MA (2017) Rail Road Wheel: Design, Performance and Manufacturing Aspects. International Journal of Mechanical and Production Engineering Research and Development Vol 7 (2) 135 - 144.

\section{Notations}

AAR Association of American Rail Roads

Class A, B, C, D Steel grades

BG Broad Gauge

MG Meter Gauge

EMU Electric Multiple Unit

L Lateral load

V Vertical Load

RWF Rail Wheel Factory (erstwhile WAP or Wheel and Axle Plant) Bangalore India

SAIL Steel Authority of India 
